\title{
Related Health Service Provider with Mental Health during Pregnancy
}

\author{
Nurul Husnul Lail ${ }^{1,2 *}$, Rizanda Machmud ${ }^{3}$, Adnil Edwin $^{3}$, Yusrawati Yusrawati $^{3}$, Anwar Mallongi ${ }^{4}$ \\ ${ }^{1}$ Department of Public Health Sciences, Faculty of Medicine, Andalas University, Padang, Indonesia; ${ }^{2}$ Faculty of Health \\ Sciences, Nasional University, Jakarta, Indonesia; ${ }^{3}$ Faculty of Medicine, Andalas University, Padang, Indonesia; ${ }^{4}$ Department \\ Environmental Health, Faculty of Public Health, Hasanuddin University, Makassar, Indonesia
}

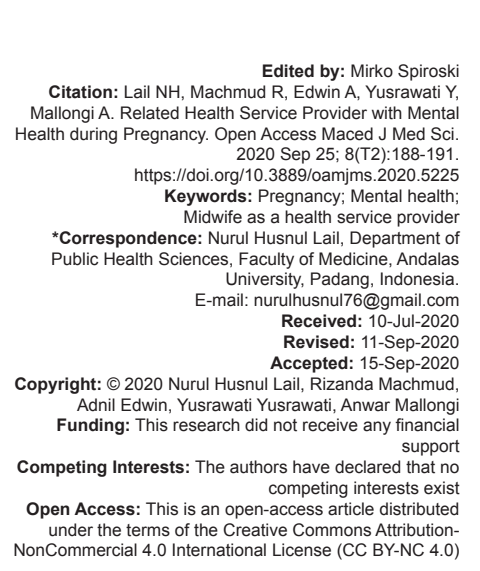

Abstract

BACKGROUND: Mental illness or mental health problems during pregnancy in low- and middle-income countries are very high; the average prevalence reaches $15.6 \%$. Subsequent research was conducted by Indian in the Jakarta and Bogor regions in the period January-June 2018 regarding the incidence of perinatal depression by $23.6 \%$ in the Bogor.

AIM: This study aimed to evaluate the mental illness or mental health problems during pregnancy in low- and middleincome countries.

METHODS: This research is qualitative research. This research was conducted in January-June 2019 in the Bogor independent practice midwife. Informants in the study came from the East Jakarta Health Office, Chair of the Indonesian Midwives Association, Head of the Health Center, Coordinating Midwives, Pregnant Women and husbands, and families of pregnant women. Data are analyzed by Regression Logistic.

RESULTS: Construction model mental health of mothers during pregnancy in independent practice midwives is very important and needs attention. Pregnancy is still considered a physical change that needs to be intervened because it is easier to handle and easily detects it. Maternal examination during pregnancy is carried out by midwives, in the implementation of mental health checks during pregnancy for pregnant women, this role has not all been carried out optimally.

CONCLUSION: This research suggests conducting socialization with midwives as well as across-related sectors to get political support in carrying out activities in health facilities and independent practice midwives.

\section{Introduction}

Mental illness during pregnancy is a public health problem that should be addressed seriously. Around $10-20 \%$ of women in the world experienced mental health problem during the 1st year following the labor. The common mental illness experienced by women include antenatal and postnatal depression, obsessive-compulsive, post-trauma stress, and postpartum psychosis [1]. The prevalence of mental illness or mental health problem during pregnancy in low-income countries reached $15.6 \%$ [2]. One of five women experienced mental health issues during pregnancy, such as depression, acute anxiety, and fear toward labor, and mild-to-moderate emotional disorders [3]. Depression and anxiety are common during pregnancy. The prevalence rate of $6 \%$ and $17 \%$ have been reported for major and minor depression, respectively [4]. Meanwhile, the prevalence rate of anxiety symptom is reported for $23 \%$ due to change in appearance which affects self-efficacy [5], and $15 \%$ for anxiety during antenatal period due to the feeling of unworthiness caused by pregnancy [6].
According to the World Health Organization, around $10 \%$ of pregnant women and $15 \%$ of postpartum women experienced mental illness, especially depression. The prevalence rate is even higher in developing countries, that is, $15.6 \%$ during the pregnancy and $19.8 \%$ following the labor [7].

Some studies were focused on decreasing the effect of pregnancy on mental health - psychology, stress and depression, knowledge, empowerment, and self-efficacy by improving the quality of pregnancy examination with antenatal care. Health workers are responsible to provide education on the psychosocial condition of pregnancy to pregnant women [8]. Besides, additional care during pregnancy should also be provided by health workers (obstetric, midwife, and nurse). This attempt is needed to foster empathy among the health workers and encourage pregnant women to check their condition, which in the long term will decrease the adverse psychological condition during the pregnancy, following the pregnancy and child care [3].

Mental health problem and other issues during pregnancy can be dangerous for pregnant women and their children. The children might experience premature birth, low birth weight, and others. In addition, social stigma, 
low self-efficacy, and negative perception will encourage pregnant women to visit health facilities [9], [10]

The prevalence rate of depression during pregnancy in Indonesia has reached $22.4 \%$ that may increase the morbidity and mortality rates of mother and children during the pregnancy and postpartum periods [11]. Mental health problems caused adverse effects to the pregnancy and the baby [12].

\section{Materials and Methods}

This study is quantitative research with explorative primary data approach. Interview is conducted with subject research 168 women pregnant at Bogor of mental health in pregnant women and the members of Indonesian midwives' branch associations to reveal the cause-effect finding. Samples were taken using an accidental sampling technique. Research time around January-April in 2019. Data analysis is carried out by regression Logistic approach analysis.

\section{Results}

\section{Related midwife as a health service provider with on mental health during pregnancy}

Through Figure 1, it can be stated that the magnitude of the t-statistic value of self-esteem for maternal mental health during pregnancy is 2309 , while for self-efficacy for maternal mental health during pregnancy is 1281 , midwife support for mental health is 1996, midwife support for self-efficacy of 1302, community support among pregnant women for maternal mental health of 1167, support of fellow pregnant women for selfefficacy of 1487, support of fellow pregnant women for self-esteem by 1519 , family support for self-efficacy by 1519 , family support for self-esteem by 1202 , husband's support for self-efficacy was 1628, and husband's support for self-esteem by 1986 . It can be concluded that all t-values are significant at a minimum of $75 \% \mathrm{Cl}$.

\section{Discussion}

Health-care provider in this case midwives and pregnant women themselves often have difficulty identifying symptoms of mental disorders during pregnancy. The high number of women who associate symptoms of antenatal and postnatal depression with "normal responses" indicates that for pregnant women, at least, the signs and symptoms of mood disorders are often indistinguishable from other typical behaviors and experiences. This seems to be supported by the findings of this study that the cause of mental disorders most often identified during the perinatal period is a factor that is directly related to pregnancy (or becoming a mother) itself [13], [14].

If pregnant women feel confident, feel confident, and convince themselves to be able to

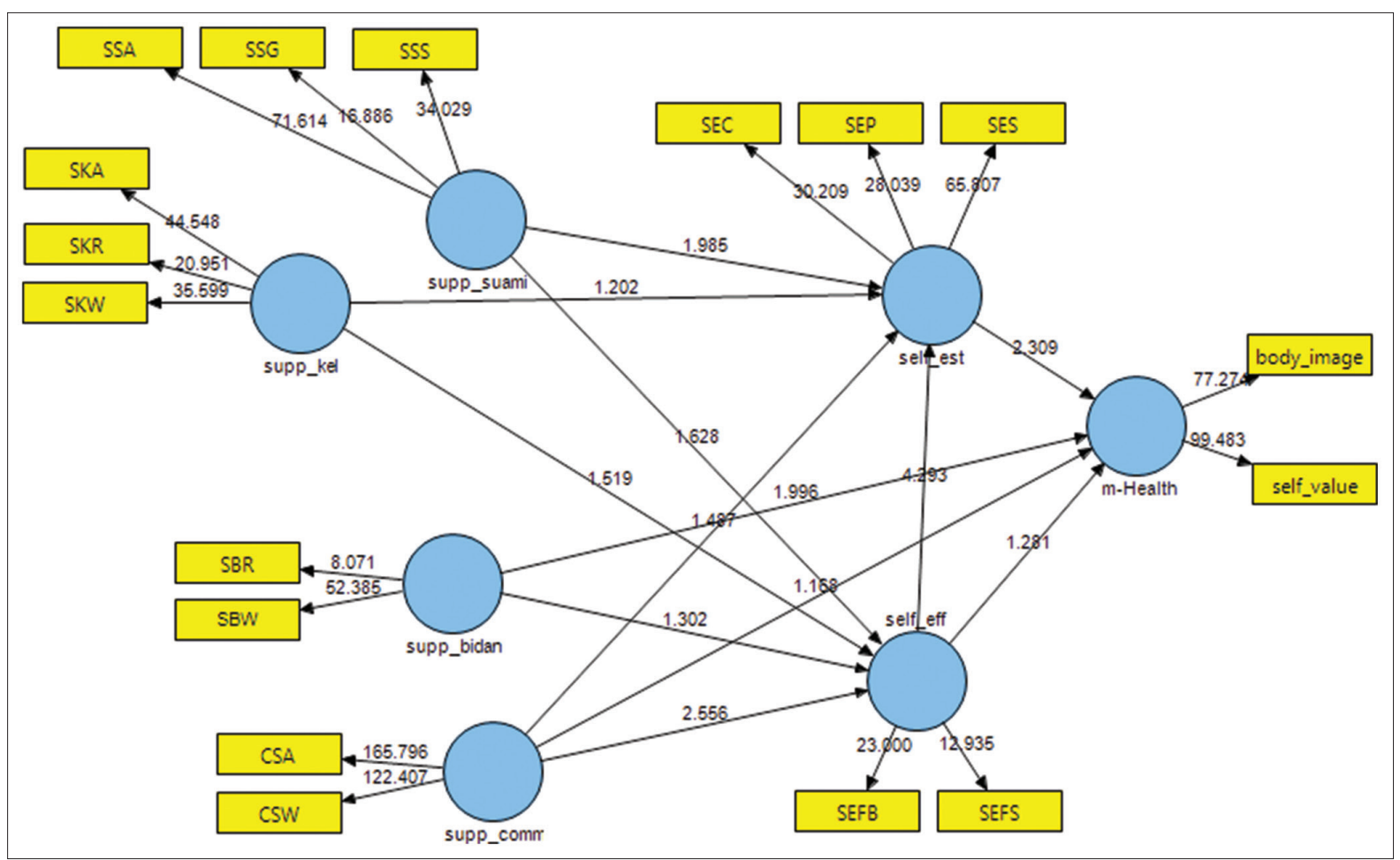

Figure 1: Output final structural model (after bootstrapping) 
be in line with mental health in pregnant women so they can get through the well pregnancy. Strategic implementation that must be carried out in the future is that the government program focuses on health development goals to reduce maternal mortality. The available programs are still not focused on psychosocial issues and their impacts as well. Psychosocial aspects of pregnant women play an important role in the well-being of mothers and fetuses, especially in primigravida mothers who have no experience. Maternal and fetal well-being can be achieved if the mother optimally adapts during pregnancy. Therefore, the prevalence of pregnancy disorders and influencing factors is very important to identify the solution and prevent future adverse effects [15].

To improve mental health services for pregnant women, it is important to develop community mental health services, including appropriate training and supervision. Training, hiring, and supporting midwives can help improve mental health service skills at LMICs. One of the main obstacles to improving mental health services in primary care settings is the low number of trained health workers trained in providing mental health-care mothers. An assessment of the need for mental health training for midwives shows the lack of training on mental health issues related to pregnancy and childbirth.

To facilitate this, the future midwives must have maternal health literacy during pregnancy, focusing on several other areas related to perinatal mental health. First, understanding more about mental health literacy associated with perinatal mental disorders, as well as increasing social support. For this purpose, investigating the mental health literacy of health workers such as midwives as well as partners and women's families can provide useful information. Second, the findings of this study seem to indicate that some differences might exist between perceptions of perinatal and non-perinatal mental disorders, which require further exploration [16].

\section{Conclusion}

There is a relationship between the role of health providers and mental health of pregnant women. Pregnant women need social support from their health workers. Hopefully, with the support of health workers, they can improve their self-efficacy and self-efficacy so that pregnant women can appreciate their role and can be sure and trust the capabilities of pregnant women. There is a balance between overall physical and mental health.

\section{References}

1. Bauer A, Parsonage M, Knapp M, lemmi V, Adelaja B. The Costs of Perinatal Mental Health Problems. London: Centre for Mental Health; 2014

2. Spedding MF, Stein DJ, Naledi T, Sorsdahl K. Pregnant Women's Mental Health Literacy and Perceptions of Perinatal Mental Disorders in the Western Cape, South Africa, Mental Health and Prevention. Netherlands: Elsevier; 2018. https://doi. org/10.1016/j.mhp.2018.05.002

3. Robertson E, Grace S, Wallington T, Stewart DE. Antenata risk factors for postpartum depression: A synthesis of recent literature. Gen Hosp Psychiatry. 2004;26(4):289-95. https://doi. org/10.1016/j.genhosppsych.2004.02.006

PMid:15234824

4. Ashley JM, Harper BD, Arms-Chavez CJ, LoBello SG. Estimated prevalence of antenatal depression in the US population. Arch Womens Ment Health. 2016;19(2):395-400.

PMid:26687691

5. Bayrampour H, McNeil DA, Benzies K, Salmon C, Gelb K, Tough S. A qualitative inquiry on pregnant women's preferences for mental health screening. BMC Pregnancy Childbirth. 2017;17(1):339. https://doi.org/10.1186/s12884-017-1512-4 PMid:28974195

6. Fairbrother N, Janssen P, Antony MM, Tucker E, Young AH Perinatal anxiety disorder prevalence and incidence. J Affect Disord. 2016;200:148-55.

PMid:27131505

7. Andersson L, Sundström-Poromaa I, Bixo $M$, Wulff $M$, Bondestam K, åStröm M. Point prevalence of psychiatric disorder during the second trimester of pregnancy: Apopulationbased study. Am J Obstet Gynecol. 2003;189(1):148-54

PMid:12861154

8. Sukhato $\mathrm{K}$, Wongrathanandha $\mathrm{C}$, Thakkinstian A, Dellow A, Horsuwansak P, Anothaisintawee T. Efficacy of additional psychosocial intervention in reducing low birth weight and preterm birth in teenage pregnancy: A systematic review and meta-analysis. J Adolesc. 2015;44:106-16. https://doi. org/10.1016/j.adolescence.2015.07.013

PMid:26265589

9. Spedding MF, Dan JS, Tracey N, Katherine S. Pregnant women's mental health literacy and perceptions of perinatal mental disorders in the Western Cape, South Africa. Ment Health Prev. 2018;11:16-23. https://doi.org/10.1016/j.mhp.2018.05.002

10. Atif N, Lovell K, Rahman A. Maternal mental health: The missing " $\mathrm{m}$ " in the global maternal and child health agenda. Sem Perinatol. 2015;39(5):345-52. https://doi.org/10.1053/j. semperi.2015.06.007 PMid:26164538

11. Publication S. Self-esteem ; a brief review; 2015.

12. World Health Organization. Promoting mental health: Concepts, emerging evidence, practice. In: Report of WHO Department of Mental Health and Substance Abuse. Geneva: World Health Organization; 2014.

13. Franks WL, Crozier KE, Penhale BL. Women's mental health during pregnancy: A participatory qualitative study. Women Birth. 2017;30(4):e179-87. https://doi.org/10.1016/j. wombi.2016.11.007

PMid:28057430

14. Marks L, Marks L. Overview of challenges to implementation of good practice in perinatal mental health promotion and management, in universal primary care and community 
services. J Public Ment Health. 2017;16(3):100-3. 2017https:// doi.org/10.1108/jpmh-03-2017-0009

15. Jablensky AV, Morgan V, Zubrick SR, Bower C, Yellachich LA. Pregnancy, delivery, and neonatal complications in a population cohort of women with schizophrenia and major affective disorders. Am J Psychiatry. 2005;162(1):79-91.

\section{PMid:15625205}

16. Pawlby S, Hay DF, Sharp D, Waters CS, O'Keane V. Antenatal depression predicts depression in adolescent offspring: Prospective longitudinal community-based study. J Affect Disord. 2009;113(3):236-43. https://doi.org/10.1016/j.jad.2008.05.018 PMid: 18602698 